\title{
Pengklasteran Dosen Berdasarkan Evaluasi Mahasiswa Menggunakan Metode Fuzzy C-Means
}

\author{
Ulfat Al-Abdaliah $^{\# 1}$, Hery Sujaini ${ }^{\# 2}$, Hafiz Muhardi ${ }^{\# 3}$

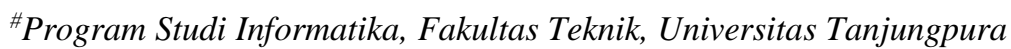 \\ Jl. Prof. Dr. Hadari Nawawi, Pontianak 78124 \\ 1ulf4t03@gmail.com \\ 2hseuntan.ac.id \\ 3hafiz.muhardieinformatika.untan.ac.id
}

\begin{abstract}
Abstrak
Fuzzy C-Means clustering (FCM) merupakan metode pengelompokkan data berdasarkan pada derajat keanggotaan ke sejumlah kelompok yang mana satu kelompok memiliki persamaan yang tinggi tetapi sangat berbeda dengan kelompok lainnya. Data clustering digunakan pada metode fuzzy C-Means adalah data evaluasi dosen terhadap mahasiswa yang mempunyai empat atribut yaitu Kesiapan Mengajar (KM), Materi Pengajaran (MP), Disiplin Mengajar (DM) dan Evaluasi Mengajar (EMJ). Penelitian ini bertujuan untuk menghasilkan aplikasi pengklasteran dosen berdasarkan evaluasi mahasiswa dengan menerapkan metode fuzzy C-Means yang akan menghasilkan informasi yang berguna untuk pihak universitas, fakultas, dan prodi. Pengujian dilakukan dengan dua cara, yaitu pengujian black box dan Partition Coeffiecient Index (PCI). Hasil pengujian black box adalah aplikasi dapat berkerja dengan baik dalam menangani suatu kemungkinan kesalahan dan pada pengujian Partition Coeffiecient Index (PCI) yaitu proses pengujian validasi fuzzy clustering dengan menghitung koefisien partisi atau PC sebagai evaluasi nilai derajat keanggotaan. Berdasarkan hasil pengujian metode Partition Coeffiecient Index (PCI) yang dilakukan diketahui bahwa perbedaan hasil evaluasi dapat terjadi antara cluster. Nilai yang semakin mendekati satu atau nilai evaluasi cluster-nya semakin tinggi, maka akan semakin baik pula tingkat kemiripan suatu cluster.
\end{abstract}

Kata kunci: Evaluasi, Clustering, Fuzzy C-Means, Black Box, Partition Coeffiecient Index (PCI)

\section{Lecturer Clustering Based on Student Evaluation Using Fuzzy C-Means}

\begin{abstract}
Fuzzy C-Means clustering (FCM) is a method of grouping data based on the degree of membership to a number of groups where one group has a high similarity but is very different from other groups. The data clustering used in the fuzzy C-Means method is the evaluation data of lecturers on students who have four attributes, namely Teaching Readiness (KM), Teaching Material (MP), Teaching Discipline (DM) and Teaching Evaluation (EMJ). This study aims to produce lecturer clustering applications based on student evaluations by applying the fuzzy CMeans method that will produce useful information for the university, faculty, and study programs. Testing is done in two ways, namely black box testing and Partition Coefficient Index (PCI). The result of black box testing is that the application can work well in handling a possible error and in testing the Partition Coefficient Index (PCI), the fuzzy clustering validation testing process by calculating the partition coefficient or PC as an evaluation of the degree of membership. Based on the results of testing the Partition Coefficient Index (PCI) method, it is known that differences in evaluation results can occur between clusters.
\end{abstract}

Keywords: Evaluation, Clustering, Fuzzy C-Means, Black Box, Partition Coefficient Index (PCI)

\section{Pendahuluan}

Dosen dan mahasiswa merupakan elemen dari suatu perguruan tinggi. Sebuah perguruan tinggi yang baik dan berkualitas sangat ditentukan oleh proses pembelajaran yang ada didalamnya. Proses pembelajaran yang baik salah satunya tergantung pada kompotensi dari dosen pengajar. Sebaik apapun kurikulum sebuah perguruan tinggi tidak akan dapat berjalan dengan baik jika tidak mempunyai dosen yang berkompetensi. Dosen yang berkompetensi akan memberikan pengaruh kepada mahasiswa yang diajar terkait pemahaman mahasiswa dalam proses bembelajaran, yang berdampak pada kualitas lulusan suatu perguruan tinggi. Kualitas proses pembelajaran salah satunya dapat ditinjau dari Evaluasi Dosen Oleh Mahasiswa (EDOM) yang dimiliki suatu perguruan tinggi. Evaluasi adalah pengukuran terhadap 
berbagai aspek tingkah laku untuk melihat perbedaan individu atau kelompok. Oleh karena tujuannya adalah untuk mengungkapkan perbedaan, maka sangat diperhatikan tingkat kesukaran dan daya pembeda masingmasing butir, serta dikembangkan acuan norma kelompok yang menggambarkan kedudukan seseorang dalam kelompok [1].

Evaluasi Dosen Oleh Mahasiswa (EDOM) adalah instrumen untuk menilai kinerja dosen dalam proses pembelajaran di akhir semester. Instrumen ini berupa daftar pertanyaan yang akan menjadi data evaluasi. EDOM juga merupakan rangkaian proses evaluasi untuk memperoleh informasi dari mahasiswa secara objektif mengenai kinerja dosen dalam proses pembelajaran . Dalam EDOM memiliki 4 kriteria yakni Kesiapan Menagajar (KM), Materi Pengajar (MP), Disiplin Mengajar (DM), Evaluasi Mengajar (EMJ).

Sebagaimana yang diketahui, dosen merupakan salah satu civitas akademik yang memegang peranan penting terhadap proses pembelajaran, maka untuk mendukung hal tersebut hasil evaluasi yang diperoleh berdasarkan EDOM selanjutnya perlu dilakukan monitoring untuk melihat kinerja dosen. Proses monitoring menjadi penting untuk dilakukan agar dapat melihat kemajuan kinerja dosen secara priodik. Salah cara untuk membantu hal tersebut dengan melakukan pengelompokkan dosen berdasarkan 4 kriteria yang ada, yaitu dengan metode clustering.

Clustering merupakan salah satu teknik untuk menentukan cluster data yang mana keberadaan tiap-tiap titik data dalam suatu cluster ditentukan oleh derajat keanggotaan. Hasil output berupa deretan pusat cluster dan beberapa derajat keanggotaan untuk tiap-tiap data [2].

Salah satu metode cluster yang dapat membantu proses nilai evaluasi mahasiswa terhadap dosen mengajar yaitu dengan metode Fuzzy C-Means. Kelebihan Fuzzy $C$ Means dapat melakukan clustering lebih dari satu variabel secara sekaligus. Fuzzy C-Means clustering adalah suatu teknik clustering yang banyak digunakan dalam aplikasi clustering. Fuzzy C-Means menerapkan pengelompokan fuzzy, dimana setiap data dapat menjadi anggota dari beberapa cluster dengan derajat keanggotaan yang berbeda-beda pada setiap cluster. Fuzzy C-Means merupakan algoritma iteratif, yang menerapkan iterasi pada proses clustering data. Tujuan dari Fuzzy C-Means adalah untuk mendapatkan pusat cluster yang nantinya akan digunakan untuk mengetahui data yang masuk ke dalam sebuah cluster.

Fuzzy C-Means merupakan suatu teknik pengelompokkan yang mana keberadaan tiap titik data dalam suatu kelompok (cluster) di tentukan oleh derajat keanggotaan. Penempatan posisi data pada cluster dilakukan dengan perbaikkan penentuan pusat cluster awal dan nilai keanggotaan secara berulang. Analisis cluster merupakan proses membagi data dalam suatu himpunan ke dalam beberapa kelompok kesamaan karakteristik data tersebut dengan data dalam kelompok lain. Kelebihan dari Fuzzy C-Means adalah dapat melakukan clustering lebih dari satu variabel secara sekaligus. Implementasi dengan metode Fuzzy C-Means digunakan untuk mengklaster data evaluasi mahasiswa. Dengan menggunakan metode ini, pengelompokkan dosen dapat ditentukan berdasarkan pada kecenderungan masing-masing data pada kelompoknya.

Salah satu contoh penelitian yang menggunakan metode Fuzzy C-Means yaitu penelitian dengan judul Menentukan Nilai Akhir Kuliah Dengan Fuzzy C-Means. Dalam penelitiannya Khoiruddin (2007) menyatakan proses pendidikan dijenjang universitas, mahasiswa dinilai dengan beberapa parameter. Parameter itu diantaranya adalah tugas, kuis, kehadiran, ujian tengah semester, dan ujian akhir semester. Masing-masing parameter itu diberi bobot sendiri. Nilai akhir kuliah akan dihitung dari perhitungan parameter-parameter tersebut dikalikan dengan bobotnya. Metode Fuzzy C-Means bisa digunakan untuk membantu menetukan nilai akhir kuliah dengan bentuk huruf. Dengan menggunakan metode ini, nilai akhir ditentukan secara lebih alami, karena berdasarkan pada kecenderungan masing-masing data pada cluster. Untuk penelitian lebih lanjut, perlu untuk diteliti waktu yang diperlukan untuk proses Fuzzy C-Means untuk data yang lebih besar.

Berdasarkan penjelasan yang sudah dipaparkan maka diperlukan pengolahan lebih lanjut terhadap data evaluasi yang telah diperoleh dengan melakukan pengklasteran dosen berdasarkan evaluasi mahasiswa menggunakan Fuzzy C-Means.

\section{Metodologi}

\section{A. Metode Penelitian}

Metodologi penelitian adalah suatu proses yang dilakukan secara ilmiah untuk keperluan sebuah penelitian. Pada penelitian ini, langkah-langkah penelitian yang dilakukan dapat dilihat pada Gambar 1 :

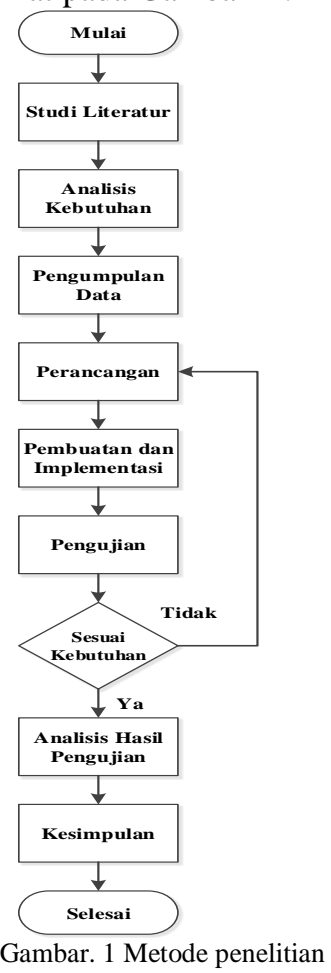


Berikut adalah penjelasan dari tahapan penelitan pada Gambar 1:

\section{1) Studi Literatur}

Studi literatur adalah tahapan yang akan melakukan mencari referensi pengetahuan yang berhubungan dengan aplikasi yang akan dibuat seperti Fuzzy C-means, clustering, perancangan Data Flow Diagram (DFD) maupun melalui penelitian penelitian sebelumnya. Tujuan utama studi literatur dalam penelitian ini adalah untuk mengetahui tentang permasalahan pengelompokan data EDOM, cara perancangan aplikasi serta penyelesaian masalah tersebut dengan logika Fuzzy. Studi literatur dimulai dengan mempelajari penelitian sebelumnya yang berkaitan tentang teori Fuzzy C-Means, pemanfaatan dan implementasinya dalam penyelesaian masalah. Kemudian dilakukan pencarian referensi tentang DFD dan penggunaannya dalam perancangan aplikasi. Tahap akhir studi literatur dalam penelitian ini adalah mempelajari cara pengujian untuk mengevaluasi aplikasi serta perhitungannya menggunakan pengujian black box dan PCI.

Logika Fuzzy adalah salah satu metode dengan sistem cerdas yang telah berkembang saat ini serta saat itu pertama kali dikemukakan oleh Lotfi A. Zadeh pada tahun 1965 [3]. Fuzzy secara bahasa diartikan sebagai kabur atau samar-samar. Suatu nilai dapat bernilai benar atau salah secara bersamaan. Dalam Fuzzy dikenal derajat keanggotaan yang memiliki rentang nilai 0 (nol) hingga 1 (satu), berbeda dengan himpunan tegas yang memiliki nilai 1 atau 0 (ya atau tidak). Logika Fuzzy merupakan logika yang memiliki nilai kekaburan atau kesamaran (fuzziness) antara benar dan salah. Dalam teori logika Fuzzy suatu nilai biasa bernilai benar atau salah secara bersama. Namun berapa besaran keberadaan dan kesalahan suatu tergantung pada bobot keanggotaan yang dimilikinya. Logika Fuzzy memiliki derajat keanggotaan dalam rentang 0 hingga 1 .

Logika fuzzy mampu membentuk perilaku reward yang dinamis sehingga meningkatkan kualitas reward yang diberikan kepada pelanggan. Input yang digunakan untuk menentukan reward adalah banyaknya transaksi, banyak produk dipilih dan total biaya pesanan. Hasil dari penelitian ini, logika fuzzy dapat menghasilkan perilaku reward yang lebih dinamis [4].

Analisis cluster atau analisis kelompok merupakan teknik analisa data yang bertujuan untuk mengelompokan individu atau objek ke dalam beberapa kelompok yang memiliki sifat berbeda antar kelompok, sehingga individu atau objek yang terletak di dalam satu kelompok akan mempunyai sifat relatif homogen [5].

Analisis cluster merupakan suatu teknik yang dipergunakan untuk mengelompokkan objek atau kasus ke dalam kelompok yang relatif homogen yang disebut cluster. Objek dalam setiap kelompok cenderung mirip atau sama dan tidak berbeda jauh (tidak sama) dengan objek dari cluster lainnya. Objek yang dikluster bisa berupa produk (barang dan jasa), makhluk hidup (tumbuhan dan hewan), atau orang (disebut responden, konsumen, partisipan, atau yang lain). Objek tersebut akan diklasifikasikan ke dalam satu atau lebih cluster sehingga objek-objek yang berada dalam satu cluster akan mempunyai kemiripan satu dengan yang lain.

Fuzzy C-means Clustering (FCM) adalah suatu teknik pengelompokkan data yang mendasarkan pada derajat keanggotaan di tiap-tiap data [6]. Fuzzy C-means menerapkan pengelompokan Fuzzy, dimana setiap data dapat menjadi anggota dari beberapa cluster dengan derajat keanggotaan yang berbeda-beda pada setiap cluster. Fuzzy C-means merupakan algoritma iteratif, yang menerapkan iterasi pada proses clustering data. Tujuan dari Fuzzy C-means adalah untuk mendapatkan pusat cluster yang nantinya akan digunakan untuk mengetahui data yang masuk ke dalam sebuah cluster.

\section{2) Analisis kebutuhan}

Analisis kebutuhan merupakan tahapan menganalisa dan memahami kebutuhan pada penelitian yang sedang dilakukan melalui cara cluster atau pengelompokkan. Ada pun dasar melakukan pengelompokkan karena data yang didapat pada penelitian ini melebihi 1 kriteria. Oleh karena itu hanya dengan cluster data dapat diolah. Dengan menggunakan metode cluster maka hasil yang di dapatkan bisa beragam.

\section{3) Pengumpulan Data}

Pengumpulan data yaitu dengan cara mengambil data yang sudah ada di website EDOM. Setelah itu data yang di dapat langsung diklasterkan. Dalam EDOM terdapat 4 kriteria penilaian yaitu Kesiapan Mengajar (KM) terdiri dari 8 pertanyaan, Materi Pengajar (MP) terdiri dari 3 pertanyaan, Disiplin Mengajar (DM) terdiri 4 pertanyaan dan Evaluasi Mengajar (EMJ) terdiri dari 2 pertanyaan.

\section{4) Perancangan}

Perancangan dilakukan berdasarkan analisis kebutuhan dan pengumpulan data yang telah dilakukan. Ada beberapa tahapan yang dilakukan dalam perancangan aplikasi yaitu perancangan perancangan diagram DFD, flowchart, arsitektur aplikasi, spesifikasi basis data dan perancangan antarmuka aplikasi.

Data Flow Diagram adalah sebuah tool yang digunakan untuk membuat diagram dengan menggunakan beberapa simbol sederhana untuk mengilustrasikan aliran data antara entitas eksternal, aktivitas proses, dan elemen penyimpanan data [7].

Data Flow Diagram adalah suatu model logika data atau proses yang dibuat untuk menggambarkan darimana asal data atau proses yang dibuat untuk menggambarkan darimana asal data dan kemana tujuan data yang keluar dari sistem, dimana data disimpan, proses apa yang menghasilkan data tersebut dan interaksi antara data yang tersimpan dan proses yang dikenakan pada data tersebut [8].

Flowchart adalah Suatu bagan yang menggambarkan arus logika dari data dalam suatu program dari awal sampai akhir. Bagan alir program merupakan alat yang berguna bagi programmer untuk mempersiapkan program yang rumit [9].

\section{5) Pembuatan dan Implementasi}


Tahap ini akan dilakukan pembuatan aplikasi berdasarkan analisis kebutuhan dan perancangan aplikasi yang telah dilakukan pada tahapan sebelumnya. Tahap implementasi keseluruhan sistem yakni tahap pembuatan perangkat lunak dengan melakukan pengkodingan terhadap hasil rancangan yang sudah didefinisikan sebelumnya menjadi sebuah program aplikasi.

Pembuatan yang dilakukan pada penelitian ini berbasis web. World Wide Web atau yang dikenal juga dengan istilah web adalah suatu system yang berkaitan dengan dokumen digunakan sebagai media untuk menampilkan teks, gambar, multimedia dan lainnya pada jaringan internet [10] .

Pembuatan web pada penelitian ini berkonsep web framework. Web framework adalah kerangka kerja perangkat lunak yang dirancang untuk mendukung pengembangan aplikasi web termasuk web service, web resources dan web API. Web framework menyediakan cara standar untuk membangun dan mengembangkan aplikasi web dan membuat pekerjaan pengembang menjadi lebih mudah. [11].

Konsep framework pada penelitia ini adalah django. Django adalah web framework berbasis bahasa pemrograman Python. Django adalah web framework Python yang didesain untuk membuat aplikasi web yang dinamis, kaya fitur dan aman. Django yang dikembangkan oleh Django Software Foundation terus mendapatkan perbaikan sehingga membuat web framework yang satu ini menjadi pilihan utama bagi banyak pengembang aplikasi web [12]. Python adalah bahasa pemrograman interpretative multiguna dengan filosofi perancangan yang berfokus pada tingkat keterbacaan kode [13].

\section{6) Pengujian}

Pengujian dilakukan dengan menggunakan metode black box dan Partition Coefficient Index (PCI). Black box merupakan Teknik pengujian perangkat lunak yang berfokus pada spesifikasi fungsional dari perangkat lunak. Black box Testing bekerja dengan mengabaikan struktur kontrol sehingga perhatiannya difokuskan pada informasi domain. Black box memungkinkan pengembang software untuk membuat himpunan kondisi input yang akan melatih seluruh syarat-syarat fungsional suatu program [14].

Pengujian black box yakni pengujian yang digunakan pada fungsional aplikasi yang telah dibuat untuk melihat kesalahan pada aplikasi. Sedangkan pengujian Partition Coefficient Index (PCI) yakni pengujian yang dilakukan sebagai evaluasi nilai derajat keanggotaan [15].

\section{7) Analisis hasil pengujian}

Analisis hasil pengujian dilakukan untuk mengetahui apakah aplikasi yang dibuat telah menghasilkan hasil yang sesuai dengan perancangan yang sudah di tentukan. Pada hasil analisis pengujian dapat digunakan sebagai dasar penarikkan kesimpulan.

\section{8) Kesimpulan}

Kesimpulan dirumuskan berdasarkan hasil pengujian yang telah dilakukan apakah aplikasi yang telah dibuat berhasil mengklasterkan nilai Evaluasi Dosen Oleh Mahasiswa (EDOM) menggunakan metode Fuzzy $C$ Means.

\section{HASIL DAN PEMBAHASAN}

\section{A. Hasil Cluster}

Berdasarkan kriteria EDOM atau Evaluasi Dosen Oleh Mahasiswa yang bertujuan untuk melihat kinerja dosen terhadap mata kuliah yang diampu, untuk itu perlu dilakukan clustering, sehingga dari hasil cluster tersebut tergambarkan kinerja dosen. Hasil proses cluster yang telah dilakukan dapat dilihat pada Tabel I, menunjukkan hasil nilai EDOM yang sudah terkelompokkan.

TABEL I

TABEL Cluster

\begin{tabular}{|c|c|c|c|c|c|}
\hline \multicolumn{6}{|c|}{ Jumlah Cluster } \\
\hline $\mathrm{C} 1$ & \multicolumn{2}{|c|}{$\mathrm{C} 2$} & C3 & $\mathrm{C4}$ & C5 \\
\hline 0 & 16,3286 & 17,058 & 14,9808 & 17,6032 & 12,5724 \\
\hline & 16,375 & 17,0674 & 15,0526 & 17,6283 & 13,3615 \\
\hline & 16,4009 & 17,073 & 15,194 & 17,779 & 13,3833 \\
\hline & 16,4775 & 17,0866 & 15,217 & 17,8088 & 13,457 \\
\hline & 16,576 & 17,1083 & 15,392 & 17,8334 & 13,4833 \\
\hline & 16,5917 & 17,1359 & 15,3958 & 17,8577 & 13,6004 \\
\hline & 16,6139 & 17,15 & 15,5596 & 17,8798 & 13,6475 \\
\hline & 16,6183 & 17,1612 & 15,5641 & 17,9629 & 13,8298 \\
\hline & 16,6988 & 17,1724 & 15,625 & 17,964 & 14,3967 \\
\hline & 16,7143 & 17,1767 & 15,6667 & 17,967 & \\
\hline & 16,7347 & 17,2064 & 15,7029 & 18,0526 & \\
\hline & 16,7798 & 17,2291 & 15,7183 & 18,1094 & \\
\hline & 16,7831 & 17,2354 & 15,7692 & 18,1328 & \\
\hline & 16,8141 & 17,2355 & 15,7917 & 18,3846 & \\
\hline & 16,8213 & 17,2481 & 15,8254 & 18,4097 & \\
\hline & 16,8601 & 17,3046 & 16,0735 & 18,4813 & \\
\hline & 16,9207 & 17,3431 & 16,1136 & 18,5079 & \\
\hline & 16,9398 & 17,3466 & 16,1667 & 18,6389 & \\
\hline & 16,9541 & 17,3766 & 16,2069 & 18,7041 & \\
\hline & 16,9954 & 17,491 & 16,2336 & 18,8 & \\
\hline & 16,9965 & 17,4917 & 16,25 & 18,8724 & \\
\hline & 17,0179 & 17,4922 & & & \\
\hline & 17,0208 & 17,5391 & & & \\
\hline
\end{tabular}

Proses cluster yang terdiri dari 98 aktivitas mengajar dari 29 dosen dilakukan sebanyak 5 cluster. Jumlah 1 cluster terdapat 1 aktivitas dari 1 orang dosen dengan nilai total 0, 2 cluster terdapat 46 aktivitas dari 20 orang dosen dengan nilai total 16,3286 sampai 17,5391, 3 cluster 21 aktivitas dari 10 orang dosen dengan nilai total 14,9808 sampai 16,25, 4 cluster terdapat 21 aktivitas dari 12 orang dosen dengan nilai total 17,6032 sampai 18,8724 dan 5 cluster terdapat 9 aktivitas dari 7 orang dosen dengan nilai 
12,5724 sampai 14,3967. Dari hasil tersebut 4 cluster terdapat nilai yang lebih tinggi dari cluster lainnya. Dengan begitu diharapkan cluster lainnya dapat mengikuti cluster lainnya.

\section{B. Pengujian aplikasi}

Pengujian aplikasi terdiri dari dua metode pengujian yaitu black box Testing dan Partition Coefficient Index (PCI). Berikut adalah hasil dari masing-masing pengujian

\section{1) Pengujian Black Box}

Pengujian black box yang dilakukan pada penelitian ini terdapat 4 skenario yang diuji. Dari 4 skenario yang diuji, pengujian black box dinyatakan berhasil dikarenakan pengujian setiap skenario berhasil dilakukan tanpa error. Hasil pengujian black box dapat dilihat pada Tabel II.

$$
\text { TABEL III }
$$

TABEL HASIL PENGUJIAN BLACK BOX TESTING

\begin{tabular}{|l|l|c|}
\hline Uji Skenario & Hasil yang diharapkan & Keterangan \\
\hline $\begin{array}{l}\text { Jumlah Cluster } \\
\text { dan jumlah iterasi } \\
\text { kosong }\end{array}$ & $\begin{array}{l}\text { Tidak berhasil } \\
\text { mengklasterkan }\end{array}$ & Berhasil \\
\hline $\begin{array}{l}\text { Jumlah Cluster } \\
\text { lebih dari 10 dan } \\
\text { Jumlah iterasi } \\
\text { lebih dari 100 }\end{array}$ & $\begin{array}{l}\text { Tidak berhasil } \\
\text { mengklasterkan }\end{array}$ & Berhasil \\
\hline $\begin{array}{l}\text { Jumlah Cluster } \\
\text { dan jumlah iterasi } \\
\text { mengisi selain } \\
\text { angka }\end{array}$ & $\begin{array}{l}\text { Tidak berhasil } \\
\text { mengklasterkan }\end{array}$ & Berhasil \\
\hline $\begin{array}{l}\text { Jumlah Cluster } \\
\text { dan jumlah iterasi } \\
\text { benar }\end{array}$ & Berhasil mengklasterkan & Berhasil \\
\hline
\end{tabular}

\section{2) Pengujian Partition Coefficient Index (PCI)}

Hasil pengujian metode Partition Coeffiecient Index (PCI) membuktikan bahwa semakin tinggi iterasi maka akan memiliki kerapatan yang tinggi pada nilai Partition Coeffiecient Index (PCI) terhadap percobaan di setiap cluster. Data yang ada pada setiap cluster bergerak atau berubah dan tidak memiliki pola khusus. Hasil pengujian Partition Coefficient Index dapat dilihat pada tabel III. TABEL IIIII

TABel HASIL Rata RATA PENGUJIAN PARTITION COEFFICIENT INDEX

\begin{tabular}{|c|c|c|c|c|}
\hline \multirow{2}{*}{ cluster } & \multicolumn{4}{|c|}{ Evaluasi PCI } \\
\cline { 2 - 5 } & Iterasi 25 & Iterasi 50 & Iterasi 75 & $\begin{array}{c}\text { Iterasi } \\
\mathbf{1 0 0}\end{array}$ \\
\hline 2 & 0,98629405 & 0,98629405 & 0,98629405 & 0,98629405 \\
\hline 3 & 0,77219121 & 0,77219438 & 0,77219438 & 0,77219438 \\
\hline 4 & 0,72058695 & 0,72109176 & 0,72109205 & 0,72109205 \\
\hline 5 & 0,62214959 & 0,62417638 & 0,62420881 & 0,62420948 \\
\hline 6 & 0,56439271 & 0,56352170 & 0,56351432 & 0,56351428 \\
\hline 7 & 0,52024845 & 0,52568821 & 0,52301441 & 0,52886544 \\
\hline 8 & 0,49396395 & 0,4927192 & 0,50282718 & 0,50696737 \\
\hline 9 & 0,46658122 & 0,46180360 & 0,46514685 & 0,46755001 \\
\hline 10 & 0,43744626 & 0,43711302 & 0,44745186 & 0,44401614 \\
\hline
\end{tabular}

\section{KESIMPULAN}

Berdasarkan dari hasil analisis dan pengujian aplikasi Pengklasteran Dosen berdasarkan evaluasi mahasiswa Menggunakan Metode Fuzzy C-Means, maka dapat disimpulkan bahwa aplikasi pengklasteran dosen berdasarkan evaluasi mahasiswa Metode Fuzzy C-Means yang dibangun telah berhasil memberikan hasil cluster berdasarkan dari Kesiapan Mengajar (KM), Materi Pengajaran (MP), Disiplin Mengajar (DM), Evaluasi Mengajar (EMJ). Hasil clustering mengajar dosen dapat digunakan untuk mengukur performa mengajar dosen disetiap matakuliah yang di ampu seperti pada penelitian ini terdapat 98 aktivitas mengajar dari 29 dosen dilakukan sebanyak 5 cluster. Jumlah 1 cluster terdapat 1 aktivitas dari 1 orang dosen dengan nilai total 0,2 cluster terdapat 46 aktivitas dari 20 orang dosen dengan nilai total 16,3286 sampai 17,5391, 3 cluster 21 aktivitas dari 10 orang dosen dengan nilai total 14,9808 sampai 16,25, 4 cluster terdapat 21 aktivitas dari 12 orang dosen dengan nilai total 17,6032 sampai 18,8724 dan 5 cluster terdapat 9 aktivitas dari 7 orang dosen dengan nilai 12,5724 sampai 14,3967. Dari hasil tersebut 4 cluster terdapat nilai yang lebih tinggi dari cluster lainnya. Dengan begitu diharapkan cluster lainnya dapat mengikuti cluster lainnya. Berdasarkan hasil pengujian black box, dapat diketahui bahwa aplikasi telah dapat berjalan dengan baik sesuai skenario yang diinginkan, skenario hasil pengujian black box dapat dilihat pada tabel II. Hasil dari pengujian Partition Coeffiecient Index (PCI) membuktikan bahwa semakin tinggi iterasi maka akan memiliki kerapatan yang tinggi pada nilai Partition Coeffiecient Index (PCI) terhadap percobaan disetiap cluster sedangkan data yang ada pada setiap cluster bergerak atau berubah dan tidak memiliki pola khusus.

Adapun hal-hal yang menjadi saran sebagai bahan pertimbangan dan masukan untuk pengembangan aplikasi agar menjadi lebih baik adalah sebagai berikut yaitu mencari metode lain untuk pengelompokkan selain metode fuzzy c-means agar dapat mengetahui perbedaan dari masing-masing metode dan aplikasi dapat dikembangkan berbasis android.

\section{DAFTAR PUSTAKA}

[1] F. W. Nugraha, S. Fauziati and A. E. Permanasari, "Sistem pendukung keputusan pemilihan varietas kelapa sawit dengan metode fuzzy c-mean," Seminar Nasional Inovasi Dan Aplikasi Teknologi Di Industri 2017, pp. B25.1-B25.7, 2017.

[2] E. Sonalita, A. Zubair, P. D. Mulya, S. R. Asriningtias and B. Nurdewanto, "Perbandingan feature selection word frequencies dan tf/idf pada proses fuzzy clustering," Seminar Nasional Sistem Informasi (SENASIF), pp. 2087-2093, 2019.

[3] W. C. Sari and K. D. Tania, "Penerapan knowledge management system (KMS) pada bagian pusat komputer (Puskom) IAIN Bengkulu dengan metode fuzzy case based reasoning (FCBR)," Prosiding Annual Research Seminar 2019 , vol. 5, no. 1, pp. $247-$ 255, 2020.

[4] "87 Model gamifikasi menggunakan logika fuzzy untuk penentuan reward pelanggan pada e-commerce," Techno.com, vol. 19, no. 1, pp. 87-96, 2020.

[5] A. D. Muryadi, "Model evaluasi program dalam penelitian evaluasi," Jurnal Ilmiah PENJAS, vol. 3, no. 1, pp. 1-16, 2017.

[6] B. Bunardi, D. S. Naga and D. Arisandi, "Pengembangan aplikasi ecommerce produk lokal dan data kependudukan pada desa giritengah, borobudur," Computatio: Journal of Computer Science and Information Systems, vol. 3, no. 1, pp. 77-84, 2019.

[7] F. T. Yuniko and F. K. Putra, "Penerapan teknologi informasi web programing untuk meningkatkan pelayanan publik dalam bidang kebijakan administrasi kependudukan," JOISIE Journal Of Information System And Informatics Engineering, vol. 1, no. 1, pp. 13-19, 2017. 
[8] D. Saputra and R. F. Aji, "Analisis perbandingan performa web service rest menggunakan framework laravel, django dan ruby on rails untuk akses data dengan aplikasi mobile (Studi Kasus: Portal E-Kampus STT Indonesia Tanjungpinang)," Bangkit Indonesia, vol. 2, no. VII, pp. 17-22, 2018.

[9] D. S, B. A and R. A, Django: Web Development with Python, Birmingham : Packt Publishing, 2016.

[10] I. K. S. Buana, "Aplikasi untuk pengoprasian komputer dengan mendeteksi gerakan menggunakan opencv python," Prosiding SINTAK 2018, pp. 189-194, 2018.

[11] T. S. Jaya, "Pengujian aplikasi dengan metode blackbox testing boundary value analysis (studi kasus: kantor digital politeknik negeri lampung)," Jurnal Informatika: Jurnal Pengembangan IT (JPIT), vol. 3, no. 2, pp. 45-48, 2018.

[12] A. F. Zuhri, A. Ahmad, I. Parlina, R. Dewi and Solikhun, "Sistem informasi data rehabilitasi narkoba pada badan narkotika nasional kota (BNNK) Pematangsiantar," Seminar Nasional Teknologi Komputer \& Sains (SAINTEKS), pp. 255-260, 2020

[13] M. W. Talakua, Z. A. Leleury and A. W. Talluta, "Analisis cluster dengan menggunakan metode k-means untuk pengelompokkan kabupaten/kota di provinsi maluku berdasarkan indikator indeks pembangunan manusia tahun 2014," Jurnal Ilmu Matematika dan Terapan, vol. 11, no. 2, pp. 119-128, 2017.

[14] A. Ramadhan, Z. Efendi and Mustakim, "Perbandingan K-Means dan Fuzzy C-Means untuk pengelompokan data user knowledge modeling," Seminar Nasional Teknologi Informasi, Komunikasi dan Industri (SNTIKI) 9, pp. 219-226, 2017.

[15] R. Irviani and R. Oktaviana, "Aplikasi perpustakaan pada SMAN 1 Kelumbayan Barat menggunakan visual basic," Jurnal TAM (Technology Acceptance Model), vol. 8, no. 1, pp. 63-69, 2017. 